\title{
Values' family flow: associations between grandparents, parents and adolescent children
}

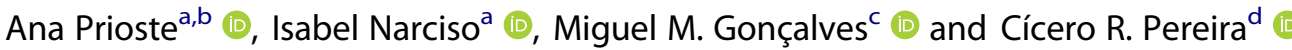 \\ ${ }^{a}$ Faculdade de Psicologia, Universidade de Lisboa, Lisboa, Portugal; ${ }^{b}$ Escola de Psicologia e de Ciências da \\ Vida, COPELABS, Universidade Lusófona, Lisboa, Portugal; ' ${ }^{C}$ sscola de Psicologia, Universidade do Minho,

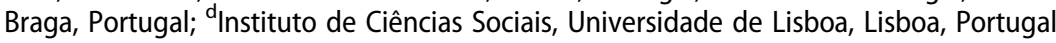

\begin{abstract}
The present study analyzed cross-generational trends in values and family patterns of value association across three generations (grandparents, parents and children). In this study, 101 family triads with adolescent children $(N=303)$ completed questionnaires assessing personal values. Grandparents' values (Generation 1) were measured through parents' perceptions of their own parents. In general, parents prioritize collectivist values, and there is an increased focus on individualist values across generations. Fathers' individualist values mediate the relationship between their perceptions of grandfathers' individualist values and grandchildren's individualist values. There is no family association of collectivist values. The article outlines the implications of the increasing adherence to individualism and hypothesizes that the adherence of individualist values across families with adolescent children is a pathway to maintenance of family cohesion and cooperation. The role of fathers and the paternal lineage on adolescents' acquisition of values are discussed.
\end{abstract}

\section{ARTICLE HISTORY}

Received 27 August 2015

Accepted 3 May 2016

\section{KEYWORDS}

Values; family; grandparents; parents; adolescents

Values are guiding principles for actions and decisions used to evaluate people and events (Rokeach, 1973; Schwartz, 1992) and are a central content of cultural transmission (Cavalli-Sforza, 1993; Knafo \& Schwartz, 2009; Schönpflug, 2009). Analyzing the continuity or change of culture (e.g. coping with the socioeconomic crisis or the collapse of a political system) through cross-generational trends of values can be a window to the study of cultural transmission processes (Schönpflug, 2009). According to an ecocultural model of intergenerational relations, cultural transmission processes, directions and outcomes are affected by (and affect) the agents - and their relationships - who is involved, what is transmitted, and the cultural context in which transmission takes place (Brofenbrenner, 1979; Trommsdorff, 2009). Literature differentiates three types or channels of transmission through which different content can be transmitted: vertical, between parents and children; oblique, through socialization institutions and other agents; and horizontal, among peers (Berry, Poortinga, Segall, \& Dasen, 2002; Cavalli-Sforza \& Feldman, 1981; Schönpflug \& Bilz, 2009). 
A large body of studies focused on vertical transmission pointed to the role of the parent-child relationship as a basic transmission belt - i.e. a mode of acquiring the cultural script or cultural values (Schönpflug, 2001) - in this relational, bidirectional and continuous process (Phalet \& Schönpflug, 2001; Pinquart \& Silbereisen, 2004; Roest, Dubas, \& Gerris, 2009; Schönpflug \& Bilz, 2009; Trommsdorff, 2009). According to Barni, Ranieri, and Scabini (2012) similar parent-child values are an outcome of the values transmission process. Therefore, similarities between parents and children have often been assumed to be a sign of successful transmission and socialization (Trommsdorff, 2009), because it is one of the basic family functions allowing synchronization among behavioral self-regulation, social expectations, identification with the social group, and loyalty to members (Schwartz \& Bardi, 2001). The clinical literature highlights the relevance of family mythology in the construction of personal values insofar as these are parts of identity that stabilize behavioral patterns (Caprara, Schwartz, Capanna, Vecchione, \& Barbaranelli, 2006; Trommsdorff, 2009) and provide coherence and continuity to personal narratives (Linares, 1996). Furthermore, values relate to family and individual wellbeing (Ghazarian, Supple, \& Plunkett, 2008) and a diversity of risk behaviors (Bond \& Chi, 1997; Goodwin et al., 2002).

In the present study, which aims to contribute to knowledge on the intergenerational transmission of values, we focus on vertical associations of collectivist and individualist values and we analyze cross-generational trends in values as well as the connection of parents' perception of grandparents' socialization values (PPGS) with the value association between parents (Generation 2, G2) and adolescent children (Generation 3, G3).

Several reasons justified this study. Literature suggests that similarity between parents' and children's values vary as a function of the content of values (e.g. Knafo \& Schwartz, 2009; Pinquart \& Silbereisen, 2004; Trommsdorff, 2009) and their relevance for agents, culture and families (Barni et al., 2012; Trommsdorff, 2009). Schwartz' theory of basic individual values proposes the order of the values around the circular motivation continuum (Schwartz, 1992). Based on the chance of distinguish several levels of abstraction within a motivational hierarchy, Schwartz et al. (2012) suggested a high order motivational principle organizing individuals' values: the focus on personal versus social outcomes. Given the importance of values' content on transmission and the labels used by some researchers (e.g. Schönpflug \& Bilz, 2009), in the present study, we organized Schwartz Value Survey (SVS) values thought the labels: collectivist values to refer to group-oriented or values focused on social outcomes; and individualist values to mean self-oriented values or values focused on personal outcomes (Prioste, Narciso, Gonçalves, \& Pereira, 2015, 2016).

The increase in average life expectancy may lead to a longer coexistence of three family generations, increasing opportunities for close relationships and influencing the transmission of processes and values (Silverstein, Giarrusso, \& Bengtson, 2003; Trommsdorff \& Nauck, 2006; Uhlenberg, 2005). Some studies have revealed the significant role of grandparents on their grandchildren's lives (Bengtson, 2001) as confidants (Silverstein \& Marenco, 2001) and as experienced storytellers who integrate history and family traditions with the cultural context (Pratt \& Fiese, 2004). In spite of this, the role of extended family, particularly of grandparents, has been ignored. Most studies on value transmission focus on the members of a nuclear family, analyzing value transmission across two generations (e.g. Barni, Ranieri, Scabini, \& Rosnati, 2011; Boehnke, 2001; Garnier \& Stein, 1998; Knafo 
\& Schwartz, 2003, 2009; Phalet \& Schönpflug, 2001; Pinquart \& Silbereisen, 2004; Roest, Dubas, \& Gerris, 2009). Although some studies have included three generations (e.g. Barni et al., 2012; Schönpflug \& Bilz, 2009), many of them focused on analysis with female samples (grandmother, G1, and mother, G2) crossed with G3 (e.g. Kalish \& Johnson, 1972; Sabatier \& Lannegrand-Willems, 2005; Trommsdorff, 2009), and there is an underrepresentation of studies of male samples of the G1 (maternal and paternal grandfathers). To our knowledge, no previous studies have examined the role played by PPGS on G2G3's value association. In line with some authors (e.g. Grusec \& Goodnow, 1994; Knafo \& Schwartz, 2009), we speculate that G2's values are a mediator between PPGS and G3's values. We examined PPGS on the assumption that ratings given by G2 as recipients were a good indicator of transmitted values. Thus, this study connects grandparents', parents' and adolescents' values, and considers both the importance of perception accuracy of parental values on the values transmission process (Grusec \& Goodnow, 1994; Knafo \& Schwartz, 2003, 2009) and the parent-child relationship as a transmission belt (Trommsdorff, 2009).

Globally, the impact of social changes (e.g. changes in work structures and the increasing entry of women/mothers into the workplace) on value similarities and dissimilarities across generations and on intergenerational relationships have been largely emphasized (Bengtson, Biblarz, \& Roberts, 2002; Constanzo \& Hoy, 2007; Trommsdorff, 2009). Furthermore, the 2008 global macroeconomic recession led to a social and economic crisis, increasing unemployment and political instability (Brooks-Gunn, Schneider, \& Waldfogel, 2013; DeVogli, 2014). Thus, couples' relationships, parenting function and children's adjustments were influenced (Conger, Rueter, \& Conger, 2000). Multiple agents have a pivotal role in co-construction, internalization, changes in valuation, and the intergenerational transmission of values, whereby oblique and/or horizontal transmissions may or not coincide with the vertical transmission, enhancing or undermining it (Trommsdorff, 2009). The balance between generational changes in valuation and transmission underlines the significance of cultural anchorage and collective memory (Halbwachs, 1968) for adaptive social functioning (Sabatier \& Lannegrand-Willems, 2005), explaining the relevance of some values as life-guiding principles (Roest, Dubas, \& Gerris, 2009) and the homogeneity of content transmitted by different agents (Schönpflug, 2009).

\section{Intergenerational transmission of values - processes and variables}

Within the family, different generations may have different levels of adherence to social values while the family transmission of values is occurring. This situation explains the perpetuation of differences among families, generations and social groups (Sabatier \& Lannegrand-Willems, 2005). Differences and similarities of values between generations can be conceptualized as a bipolar continuum (Phalet \& Schönpflug, 2001), from an absence of differences (total transmission) to an absence of similarities (total transformation). In fact, each of these poles could be dysfunctional, in terms of society and the family: total transmission would not allow creativity and change to face challenges - unenlightened (Schönpflug, 2009) societies and families; and total transformation would not allow the preservation of cooperative and supportive relationships between generations (Schwartz \& Bardi, 2001) - enlightened (Schönpflug, 2009) societies and families. 
Different theoretical conceptualizations developed explanations regarding intergenerational similarities and differences on values. According to the model of culture-specific developmental paths (Rothbaum, Pott, Azuma, Miyake, \& Weisz, 2000), similarities in values among the older and younger generations are stronger in societies where collectivist values are more valued than in individualistic societies. Intergenerational differences in value orientations and higher selectivity in the transmission of values should be related to the preference for individualist values (Rothbaum et al., 2000). Furthermore, several studies (e.g. Barni et al., 2012; Barni, Knafo, Ben-Arieh, \& Haj-Yahia, 2014) have shown that the same socialization context and group specificities (i.e. the socio-cultural interactions and family environment) lead to similar specific values - stereotype effect (Cronbach, 1955). From a developmental perspective, intergenerational differences in values can be related to developmental dynamics - i.e. different stages and respective tasks in the lifecycle - and to a different historical impact on socialization (Trommsdorff, 2009).

According to some authors (e.g. Cavalli-Sforza, Feldman, Chen, \& Dornbusch, 1982; Schönpflug \& Bilz, 2009), the result of intergenerational transmission of values is similarity between parents' and offspring's values. The levels of similarity and dissimilarity of values have been described in terms of internalization. The value acquisition model, proposed by Grusec and Goodnow (1994) within an information-processing framework, suggests that the transmission of values across generations involves a process of internalization with two steps: (1) the child's perception of the parental message with accuracy or inaccuracy; and (2) the acceptance or rejection of the perceived message. Different conditions affect these two steps. Accuracy depends on the child's attention to the parents' message and the clarity or redundancy of the message (Grusec \& Goodnow, 1994; Knafo \& Schwartz, 2003, 2009). Acceptance or rejection depends on the child's motivation toward the message and the perception of the message as appropriate and as a facilitator of self-generated feelings (Grusec \& Goodnow, 1994). The filter model (Schönpflug \& Bilz, 2009) proposes that the intensity of transmission between parents and child depends on filters, namely the parents' motivation to transmit specific values and the child's acceptance of parental influence. Both models emphasize the acquisition of values as a co-construction process, highlighting parents' choices and motivation about which values they intend to transmit and children's choices to accept or reject those values. Furthermore, both models also underline the selectivity of the transmission process regarding the content of transmission.

The literature lacks consensus on the question of which values are most important to parents, or what values should be transmitted to children to reinforce similarities between parents and children. According to the evolutionary perspective (Schönpflug, 2001; Schönpflug \& Bilz, 2009), parents are more likely to transmit collectivist than individualist values because the former serve the in-group, reinforcing cohesion and cooperation. This perspective has been confirmed in the literature, which has found stronger intergenerational similarities for collectivist than for individualist values between parents and adolescents (e.g. Friedlmeier \& Trommsdorff, 2011; Roest, Dubas, Gerris, \& Engels, 2009; Schönpflug, 2001). However, the salience perspective proposes that values that are more salient (i.e. important and prominent) for family members are more likely to be transmitted, regardless of the value content (Pinquart \& Silbereisen, 2004). 
The literature pointed to several relational and socio-developmental influential factors on value similarity between parents and their offspring, namely, quality of the parentchild relationship (Schönpflug \& Bilz, 2009; Trommsdorff, 2009), socioeconomic status (SES) (Rosen, 1964), family size (Rosen, 1964), parenting style (Schönpflug \& Bilz, 2009), parents' age (Rosen, 1964) and education (Schönpflug \& Bilz, 2009), quality of the parents' relationship (Schönpflug \& Bilz, 2009), sibling position (Schönpflug \& Bilz, 2009), gender of child and parent (Phalet \& Schönpflug, 2001), interparental value agreement (Knafo \& Schwartz, 2003, 2009) and socio-cultural environment (Barni et al., 2012).

The literature is not consistent on the role of parents' sex in the similarity between parent-child values. Although some studies (e.g. Flor \& Knapp, 2001) suggest the effectiveness of direct parental modeling of desired behavior in both same-sex and cross-sex parent-child dyads, a small number of studies have provided support for stronger intergenerational similarity of values within same-sex relationships than within cross-sex relationships (Axinn \& Thornton, 1993; Copen \& Silverstein, 2008). In this sense, and according to gender role models of socialization theory, it has been suggested that the similarity of gender can favor relationship alliance, increasing value transmission (Copen \& Silverstein, 2008). So, fathers transmit their values primarily to their sons, and mothers transmit theirs primarily to their daughters (Vollebergh, Iedema, \& Raaijmakers, 2001). Several studies (e.g. Boehnke, 2001; Knafo \& Schwartz, 2003) have found a stronger association between mother-child values than between father-child values, which can be explained by an evolutionist perspective through different levels of parental investment in their children (Geary, 1998; Parke, 2002) and the emotional closeness of the intergenerational dyads (Euler, Hoier, \& Rodhde, 2009). However, some studies have concluded that fathers have a greater impact on their children, regardless of sex, in areas in which they are more involved than mothers or in which they serve as the primary role model (Hosley \& Montemayor, 1997). For example, Roest, Dubas, and Gerris (2009) found that fathers are more influential in values associated with children's work. Friedlmeier and Friedlmeier's (2012) study of a sample of Romanian families found that fathers play a more dominant role in the process of children's value formation and suggested that it could be a consequence of a traditionalist society.

Given that transmission belts are structured as intergenerational investment patterns (Euler et al., 2009), family lineage of grandparents and grandparents' sex can be influential in value transmission (Copen \& Silverstein, 2008; Euler \& Weitzel, 1996). Regardless of family lineage, grandmothers are more involved with grandchildren in leisure, social and religious activities (Silverstein \& Marenco, 2001). Some studies (e.g. Euler \& Weitzel, 1996; Uhlenberg \& Hammill, 1998) suggested that maternal grandparents, particularly maternal grandmothers, are likely to be in touch with grandchildren more frequently and engage in more caring activities for their grandchildren than paternal grandparents. According an evolutionary perspective (Euler et al., 2009; Euler \& Weitzel, 1996), the combination between assistance in sex-specific reproductive strategy and paternity uncertainty justifies the different investment by grandparents. However, a study by Copen and Silverstein (2008) on religious values transmission found no differences according to the family lineage of grandparents. 


\section{Portugal's social and economic factors}

Considering that the present study was conducted in Portugal, there are some social and economic factors that we should take into consideration in order to a better understanding the cross-generational value trends and their intra-family transmission. Over 41 years (1933-1974) Portugal was under a dictatorship (Estado Novo) which imposed religious, conservative and nationalist values through oppression (Rosas, 2001). A large period of G1 life was characterized by poverty, fascism, absence of politically democratic context, cultural and social restrictions, relational and individual control that influenced people's values, routines, professional choices and relationships (Rosas, 2001). Following the collapse of the dictatorship (through the Carnation Revolution in 1974), G2 and G3 people were able to live in a democratic sociopolitical environment. They started to have educational access, and the influence of religious values diminished (Barreto, 2013).

Following the 2008 global macroeconomic crisis, Portugal is still dealing with economic and political instability. In 2012, the unemployment rate rose to $15 \%$, and in $201327.4 \%$ of the population was at risk of poverty and/or social exclusion (INE, 2013). It is well known that adverse economic conditions threatened families' key functions - i.e. to provide basic means of subsistence for its members (Voydanoff, 1990) - and many of them were forced to cut expenditure in several areas, such as food, health and education (SEDES, 2012). Macroeconomic crisis impacts on several variables that also influence similarity of values between parents and their offspring (e.g. family functioning, relationship and parenting quality). For example, a recent Portuguese study conducted by Ferreira, Pedro, and Francisco (2015) found direct effects between economic pressure and marital conflict.

\section{Current study}

In the present study, we analyze cross-generational trends in values across three generations; and explore the associations of collectivist and individualist values in families with adolescent children. In order to do so, we consider the PPGS and the parents' values (G2) as predictors of children's values (G3); and the perceptions of maternal and paternal grandparents' socialization values (G1) as predictors of mothers' and fathers' values (G2), respectively; and also test the mediation of G2's values between PPGS and G3's values.

Regarding the cross-generational trend of values and in line with studies with Portuguese samples (e.g. Ramos, 2006), we expected all generations to prioritize collectivist values - i.e. transcending personal interests in favor of social wellbeing. Furthermore, following previous studies (e.g. Prioste, Narciso, \& Gonçalves, 2012; Sabatier \& Lannegrand-Willems, 2005), we expect adolescents, compared to older generations, to prioritize individualist values.

Despite the scarcity of studies that include G1, it is assumed that the nuclear family of G2 is a socializing agent that is more influential than the extended family (Trommsdorff \& Nauck, 2006). Furthermore, a socialization environment shared within the nuclear family tends to be more similar than one shared within the extended family. Thus, we expected greater associations between parents and their offspring's values than between grandchildren and their grandparents' values, regardless the value content. On the other hand, we expected collectivist values to be vertically connected between family generations (Schönpflug, 2001; Schönpflug \& Bilz, 2009). Individualist values might represent a threat to the 
in-group by reinforcing individual needs over family cohesion and cooperation, so these values tend not to be vertically connected (Prioste et al., 2015; Schönpflug, 2001; Schönpflug \& Bilz, 2009).

Since the influence of G1's values on G3's values can also be indirect and mediated by G2 (e.g. Sabatier \& Lannegrand-Willems, 2005) and grandparents may socialize the socializers (van Ijzendoorn, 1992), we hypothesized that PPGS values is a mediator between G2's and G3's values (e.g. Grusec \& Goodnow, 1994; Knafo \& Schwartz, 2009). Moreover, considering that similarity of values is an effective way to evaluate successful transmission (Trommsdorff, 2009), the PPGS values should predict G2's values, and G2's values should predict G3's values. If this flow occurs, the transmission process could occur through mediation, as analyzed with multiple regressions.

Following the suggestion of recent studies, we expected intergenerational investment patterns to be reflected in similarity of values within the family (Euler et al., 2009), and also stronger mother-child compared to father-child associations. Considering the discriminative investment of grandparents - i.e. the combination of assistance in sex-specific reproductive strategy and paternity uncertainty - it is likely that maternal grandparents' and grandchildren's values are more strongly associated than paternal grandparents' and grandchildren's values (e.g. Euler \& Weitzel, 1996; Uhlenberg \& Hammill, 1998).

\section{Methods}

\section{Participants}

This sample comprised 101 Portuguese intact family triads (father, mother and adolescent children) making a total of 303 participants. In the sample of children, 53.5\% were daughters and $46.5 \%$ were sons, aged between 15 and 19 years $(M=16.7 ; D P=1.48)$. Most had $10-12$ years of education (58.4\%); had no significant psychological or psychiatric complaints $(81.2 \%)$ or serious physical health problems (88.1\%); and followed religious practices $(43.1 \%)$. In the parents' sample, 50\% were mothers and 50\% were fathers, aged between 32 and 61 years $(M=46.40$; $S D=4.87$ ). Regarding educational level, $33.2 \%$ had higher education, and $28.2 \%$ had $10-12$ years of education. Most had never had significant psychological or psychiatric complaints $(86.1 \%)$ or serious health problems $(81.5 \%)$ and were believers without following religious practices (53\%). The families lived in several Portuguese geographic regions: $40.7 \%$ in Lisbon and surrounding areas, $36.3 \%$ in the North, $18.6 \%$ in the Center and $4.5 \%$ in other regions of the country. The grandparents' sample was described by parents. Most of the G1 sample had 04 years of education (50.8\%) and followed religious practices (45.6\%).

\section{Procedures}

Participants who belonged to intact families were selected from a larger sample composed of 904 people who were participating in a larger study about intergenerational family (dis) similarities of values and relationship patterns. The participants in the larger sample were composed of adolescents (age range: 15-19 years) and parents whose children were adolescents ranging from 15 to 19 years old. The adult and adolescent participants in the larger sample belonged to intact, single-parent or divorced families. For inclusion in the present study, families were required to be intact. 
Participants were recruited over a two-year period through a non-probabilistic sampling strategy using a snowball process $(81.4 \%)$ or through collaboration with the Portuguese Association of Large Families (APFN) (18.6\%). The questionnaire packs were delivered in person to participants or were mailed in the case of large families. All families were supplied with a written document about the main objectives of the research. The voluntary nature of their collaboration was also explained, and they were assured confidentiality and anonymity. Participants received no incentives for collaboration. An informed consent document was signed by all participants.

\section{Measures}

\section{Values assessment}

We measured the collectivist and individualist values using a measurement suited for this purpose. We adapted the Schwartz Value Survey (Schwartz, 1992), which was translated and adapted for Portugal by Menezes and Campos (1991) and later by Prioste et al. (2012). The SVS includes a list of 63 values, as guiding principles of participants' lives, rated on a scale ranging from (0) "Not important" to (6) 'Fundamental importance'. Each item is briefly defined in parentheses (e.g. Social order [Stability of society]). The items of the SVS allow us to assess individualist and collectivist values (Prioste et al., 2015, 2016). Collectivist values refer to group-oriented values or those focused on social outcomes such as relational, traditionalism, social concern and spirituality; and individualist values refer to self-oriented values or values focused on personal outcomes and include social power, personal achievement, personal balance and adventure.

Parents (G2) completed the SVS twice: responding about their own values and considering their PPGS values (perception of G1's values) through the question: 'How would your father and mother want you to respond to each item?' Adolescents (G3) completed the SVS by responding about their own values.

In a previous study (Prioste et al., 2012) using a sample of 630 Portuguese participants, the Cronbach's alpha for the collectivist and individualist values showed good internal consistency: collectivist $\alpha=0.88$ and individualist $\alpha=0.90$. In a recent study (Prioste et al., 2015) using a sample of adolescent Portuguese participants, the Cronbach's alpha for the collectivist and individualist values showed good internal consistency: collectivist $\alpha=0.90$ and individualist $\alpha=0.86$. In the present study, the Cronbach's alpha for collectivist and individualist values, considering each family element (maternal grandmothers and grandfathers, paternal grandmothers and grandfathers, fathers, mothers and adolescent children), also revealed good internal consistency: for the collectivist values, the Cronbach's alphas were between 0.95 (for paternal grandfathers) and 0.89 (for children); for the individualist values, the Cronbach's alphas were between 0.93 (for maternal grandmothers) and 0.83 (for fathers).

\section{Statistical analysis}

Statistical Package for Social Science version 22 (SPSS) was used for all the statistical analyses. To analyze the cross-generational trend of individualist and collectivist values across three generations, we conducted repeated-measures factorial ANOVAs. These analyses were complemented with multiple comparisons using Bonferroni adjustment at $p<$ 0.05 , to reduce the probability of type I error. 
To study the relationship between the intergenerational family associations of individualist and collectivist values, multiple linear regressions were conducted. For each value, three multiple linear regressions were conducted to analyze (first step) which PPGS values and mother's and father's value dimensions (G2) predicted the same value dimensions among children (G3); (second step) which perceptions of maternal grandparents' socialization value dimensions (G1) predicted the same value dimensions among mothers (G2); and (third step) which perceptions of paternal grandparents' socialization value dimensions (G1) predicted the same value dimensions among fathers (G2).

\section{Results}

\section{Cross-generational trends of values}

Figure 1 shows the mean scores of collectivist and individualist values across three generations. A 3 (Generation: G1 versus G2 versus G3) × 2 (Values: collectivist versus individualist) repeated-measures factorial ANOVA indicated a significant main effect of the generation on the rating of the values, $F(2,99)=45.05, p<0.001, \eta_{p}^{2}=0.48$. Multiple comparisons showed that, in general, the mean score of $\mathrm{G1}$ was lower $(M=4.33$; $S D=0.04)$ than the scores of $\mathrm{G} 2(M=4.64 ; S D=0.03)$ and $\mathrm{G} 3(M=4.60 ; S D=0.04)$ and there were no significant differences between the G3's mean score and G2's mean score.

We also found a significant main effect of the type of the values, $F(1,100)=105.85, p<0.001$, $\eta_{p}^{2}=0.51$. Multiple comparisons showed that the mean score of the individualist values was lower $(M=4.37 ; S D=0.03)$ than collectivist values mean score $(M=4.68 ; S D=0.04)$.

Importantly, there was a significant interaction between the generations and the type of values, $F(2,99)=14.06, p<0.001, \eta_{p}^{2}=0.22$, indicating that the content of values had different effects on people's ratings depending on generations. To better understand this interaction, we performed multiple comparisons with Bonferroni adjustment, comparing each generation in the individualist and collectivist values. The results showed that G1's collectivist values mean score $(M=4.52$; $S D=0.05)$ was lower than G3's $(M=$ 4.67; $S D=0.05)$ and $G 2$ 's $(M=4.83 ; S D=0.04)$ mean scores and G2's collectivist values

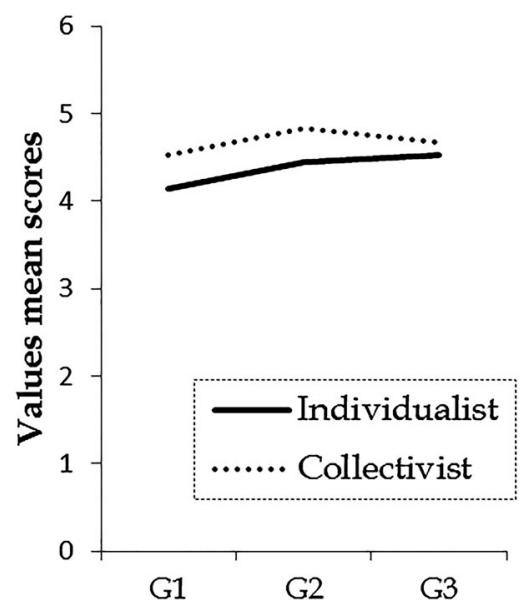

Figure 1. Mean scores of collectivist and individualist values across generations (G1, G2 and G3). 
mean score was the highest. G1's individualist values $(M=4.53 ; S D=0.04)$ was the lowest and there were no significant differences between the G3's mean score $(M=4.53 ; S D=$ $0.04)$ and $G 2$ 's $(M=4.45 ; S D=0.03)$ mean score.

\section{Regression models of family values}

Figure 2 shows the regression models for the collectivist values (Figure 2a) and for the individualist values (Figure 2b). Regarding the collectivist values, perceptions of maternal grandfathers' collectivist values were a significant predictor of mothers' collectivist values, and perceptions of paternal grandfathers' collectivist values were a significant predictor of fathers' collectivist values. These significant relations suggest that the more parents perceived that grandfathers held collectivist values, the more they adhered to these values. None of PPGS and G2's collectivist values predicted G3's collectivist values.

With regard to regression models for the individualist values, perceptions of maternal grandparents' individualist values were a significant predictor of mothers' individualist values, indicating that the more mothers perceived that their parents held individualist

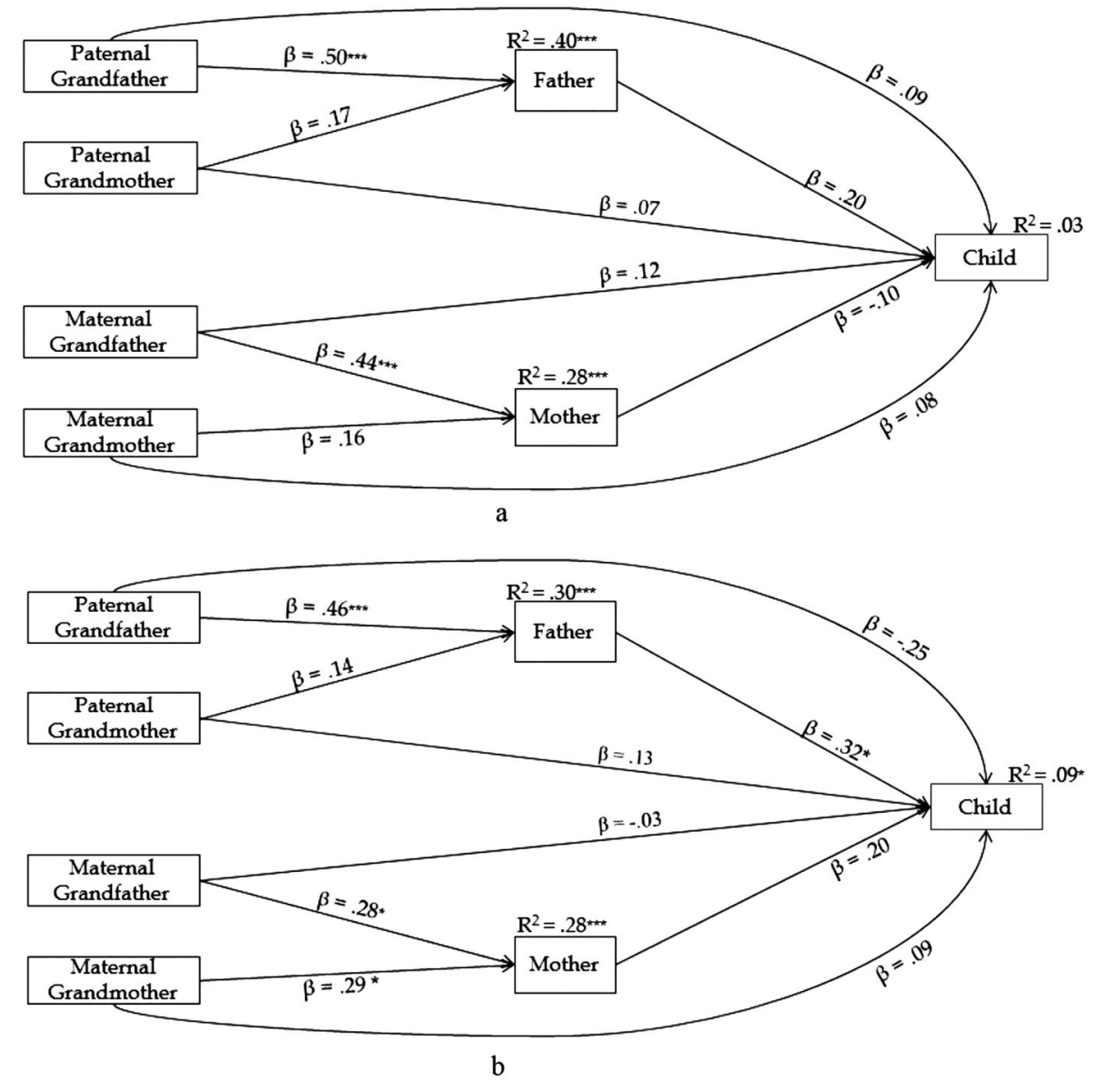

Figure 2. Intergenerational transmission model of collectivist (2a) and individualist values (2b), in families with adolescent children. 
values, the more they adhered to those values. There was a significant relation between perceptions of paternal grandfathers' and fathers' individualist values, indicating that the more fathers perceived that their fathers held individualist values, the more they adhered to these values. We found a significant relation between fathers' and children's individualist values, suggesting that the more fathers adhered to individualist values, the more children also held these values.

The results of individualist values suggested the possibility that parents' values mediate the relationship between PPGS values and grandchildren's values. Therefore, we tested the mediation of fathers' individualist values on the effects of perceptions of paternal grandfathers' individualist values on children's individualist values. The mediation effect of fathers' individualist values was reliable with 10,000 bias corrected resamples bootstrapping procedures (indirect effect $=0.11,90 \% \mathrm{CI}=0.03$ to 0.24 ; direct effect $=-0.21,90 \%$ $\mathrm{CI}=-0.37$ to -0.05 ; total effect $=-0.10,90 \% \mathrm{CI}=-0.24$ to 0.06 ).

\section{Discussion}

In the present study, we analyze family patterns of value associations across generations by examining the role played by PPGS values on G2-G3's value association as well as crossgenerational trends of values. Thus, this study contributes to an understanding of the cultural transmission processes, particularly with reference to which values seem to be transmitted by which intra-familial sources and channels. Our research priorities were to study value association within families with adolescent children (Barni et al., 2011; Roest, Dubas, Gerris, \& Engels, 2009) and to explore some gaps in the literature, particularly for the Portuguese context (e.g. the absence of studies about maternal and paternal grandfathers).

\section{Cross-generational trend}

The general trend suggested by our results may indicate that, within the Portuguese culture, collectivist values could be more relevant as guiding principles. This result supports our hypothesis and previous studies (e.g. Ramos, 2006) and can be understood within the filter model (Schönpflug \& Bilz, 2009) and the value sources perspective proposed by Pereira, Camino, and Costa (2005). According to the value sources perspective, instead of simply representing basic individual needs and motivations, values express basic socially shared principles about how society should be organized and are anchored in social identities (Estramiana, Pereira, Monter, \& Zlobina, 2013). For both perspectives, the importance of the collectivist values may reflect the fundamental principles that appear to guide Portuguese society - cultural values, according to Hofstede (1980) and Inglehart (1977) - in terms of values focused on interdependence. As cultural values, values focused on social outcomes affect the development of parent-child relationships over the life span and over the generations and the related processes of the cultural transmission (Trommsdorff, 2009). Thus, homogeneity of content transmitted by different agents on oblique, horizontal and vertical transmissions (Schönpflug, 2009) enhanced the intergenerational transmission of collectivist values.

According a developmental perspective (e.g. Trommsdorff, 2009), intergenerational trends in the individualist and collectivist values suggested by our results can be explained through different developmental stages and inherent tasks in the lifecycle and to a different 
historical impact on socialization. The trends indicated by our results regarding individualist values support previous studies (e.g. Prioste et al., 2012; Sabatier \& LannegrandWillems, 2005) which suggest that new generations are likely to prioritize these values. This difference could be due to age or cohort effects. For adolescents, development challenges, as tests of their own limits, supported by metaphysical egocentrism and the belief in personal fables (i.e. belief in the non-imputability of the consequences of one's behavior), could accentuate the adoption of values such as pleasure, daring and curiosity (Prioste et al., 2012). Beyond the pronounced openness to diverse beliefs and behaviors, G3 have been profoundly influenced by cultural trends widely disseminated by the media, such as television, movies, music and the Internet (e.g. Facebook) (Jensen \& Arnett, 2012; Schlegel, 2011). Thus, this difference may be associated with the current global cultural focus on welfare and achievement, promoting and enhancing values focused on individual and here-and-now gratification (Prioste et al., 2012). The growing trend of valuing the individualist values from G1 to G3 may be related to the fact that this assessment involves the perception of G2 about G1; thus, it may be a perception that the previous generation was less focused on these values.

Our results pointed to the centrality of the collectivist values in G2 and G3 in comparison to G1. This result may be due to the several systemic levels of human development (Brofenbrenner, 1979). At the macrosystemic/chronosystemic level, it is important to note the relevance, in the Portuguese context, of the political and social development after the Carnation Revolution, a period in the history of Portugal resulting from a military coup in 1974 that overthrew the almost five decades of a dictatorial regime. With the end of the oppression experienced by G1 during the dictatorial regime, G2 and G3 have been living in a socially and politically democratic context in which they are allowed social, relational and individual freedom. Additionally, the past and present Portuguese context highlights the relevance of social values as a common familial discussion topic and guiding principles of life for G2 and G3.

Moreover, in addition to the specificity of the Portuguese context, there has been increasing connectivity to the wider world through technology. Thus, unlike G1, we can say that G2 and G3 are experts in technology, allowing them more frequent contact and expressions of appreciation, concern and care for the welfare of others through electronic, digital and face-to-face communication. We must also highlight the relevance of G3 peer groups (microsystem), particularly their influence on relational values such as friendship, loyalty and generosity, as adolescents' guiding principles of life and behavior. Furthermore, new generations seem to be more receptive to social trends, such as environmental and peace movements (Pinquart \& Silbereisen, 2004).

Regarding the chronosystemic/microsystemic level, we must underline the individual and familial developmental tasks inherent in the lifecycle stage of each generation. Accordingly, due to G1's increasing age and loss of autonomy, G2 may perceive G1 as more oriented to the past (Friedlmeier \& Friedlmeier, 2012) and to the preservation of social values, thus reinforcing security and stability (Sabatier \& Lannegrand-Willems, 2005). G2, commonly considered the sandwich generation (Trommsdorff \& Nauck, 2006; Zal, 1992), may be more focused on nurturing the individuation-socialization development of their children and caring for their own parents, hence becoming more oriented to collectivist values that are more congruent with their family concerns and needs. As the generation that rates collectivist values most highly, it is possible that the overload of caring 
requests explains the relational guidance of G2. Furthermore, this result may suggest that G2 may connect the previous and the following generation, favoring the maintenance of family identity (Cigoli \& Scabini, 2006), collective memory and social wellbeing (Halbwachs, 1968).

\section{Family intergenerational associations of values}

The results show that the collectivist and individualist values of G1 are associated with G2 values, which may be due to the assessment - i.e. G1's values involve the perception of G2 about G1- and consequently the identification of G2 with the parents. In addition, some authors (e.g. Ranieri \& Barni, 2010) suggest that there are more value associations between parents and grown children when the latter assume adult and parental roles.

The association between G2 and G3 values was only found in the individualist values, which does not support our hypothesis or other studies (e.g. Friedlmeier \& Trommsdorff, 2011; Roest, Dubas, Gerris, \& Engels, 2009; Schönpflug, 2001). These results also do not support the evolutionary perspective (Schönpflug, 2001; Schönpflug \& Bilz, 2009), according to which parents would be more likely to transmit collectivist than individualist values. In line with Trommsdorff (2009), we hypothesize that family impact on values transmission is reduced on broadly shared values that are transmitted by multiple socialization agents.

The analysis of the underlying cross-generational value trends pointed to the relevance of collectivist values across generations. However, rank-order similarity, as measured in regressions, indicates that in some families there is agreement about low importance of the group-oriented values. Accordingly, in line with evolutionary (Schönpflug, 2001) and salience perspectives (Pinquart \& Silbereisen, 2004), we hypothesize a paradox: the transmission of individualist values across families with adolescent children is a pathway to the maintenance of family cohesion and cooperation, through the mechanism of sharing the salience of the values focused on personal outcomes.

Thus, considering the two opposing perspectives (Bengtson et al., 2002) - social and family decline versus solidarity - our data provide support for both. On one hand, our results point to an increasing appreciation of individualism (social and family decline) but on the other hand, the appreciation of individualism links the family generations and points to the capacity of the family to influence next generations (social and family solidarity). Hence, we could propose the transmission of individualist values across generations as a pathway to link the family and part of family mythology (Linares, 1996).

Note that there is a masculine dominance of the transmission of individualist values: only male family elements (maternal and paternal grandfathers and fathers) transmit these values. According to research on values, individualist values are more relevant in male samples (e.g. Schwartz \& Rubel, 2005). Therefore, we hypothesize that fathers can serve as primary role models (Hosley \& Montemayor, 1997) of values associated with agency, accomplishment and social power, and they have a greater impact on their children's education in this area. Furthermore, we hypothesize that the individualist values are more relevant to fathers. Our results show that individualist values are also more important to G3. Thus, on the basis of these assumptions, our data support the salience perspective, which states that values that are more salient for family members are more likely to be transmitted (Pinquart \& Silbereisen, 2004). 
In the present study, we found an indirect association between G1's and G3's individualist values. Paternal grandfathers socialize fathers (socializer) (van Ijzendoorn, 1992), contributing indirectly to the transmission of individualist values to their grandchildren.

\section{The role of parents' gender}

Although several studies suggest that the maternal influence on children's values is stronger than the paternal influence regardless of children's sex (e.g. Barni et al., 2011; Boehnke, 2001; Knafo \& Schwartz, 2003), the results do not support our hypothesis based on intergenerational investment patterns (Euler et al., 2009), revealing no association between mothers and children. It is possible that mothers, as family gatekeepers (Geary, 1998), kin keepers (Euler et al., 2009) or guardians, are more flexible than fathers with regard to the transmission of values to their adolescent children, allowing them more autonomy to accept or reject their mothers' values (Barni et al., 2011) in an attempt to maintain proximity and family harmony and to better support their identity construction process (Sabatier \& Lannegrand-Willems, 2005). In this sense, mothers could be more comprehensive and less prescriptive, which may be reflected in a lower association between their values and those of their children. It is also possible that because of the emotional closeness of mother-child dyad (Euler et al., 2009), mothers are more involved in their children's education (in comparison to fathers, who usually have a less central role or presence), and may may need to adopt different educational practices embedded in similar aims and values (equifinality) or similar educational practices embedded in different aims and values (multifinality). Furthermore, mothers are more involved in their children's education (in comparison to fathers, who usually have a less central role or presence), and may need to adopt different educational practices embedded in similar aims and values (equifinality) or similar educational practices embedded in different aims and values (multifinality). This may be perceived by children as inconsistency in their mothers' messages about values (Knafo \& Schwartz, 2003) and consequently may diminish the power and clarity of the messages and the acceptance of their mothers' values.

Therefore, our results suggest that fathers may have a central role in children's values, calling into question parental gender-role differences, particularly the instrumental and more peripheral role commonly attributed to fathers. Nevertheless, it is possible that, compared with mothers, fathers are more prescriptive and less comprehensive, allowing children less autonomy in accepting or rejecting their values (Barni et al., 2011), directing them more clearly, increasing the accuracy of children's perceptions of their message, influencing them more than mothers, and thereby favoring the internalization of fathers' values (Grusec \& Goodnow, 1994).

On the other hand, this result can also be interpreted from an evolutionary perspective (e.g. Euler et al., 2009; Euler \& Weitzel, 1996). Fathers, comparing to mothers, need to rely more on child resemblance for investment (Porter, 1987). Children can prioritize fathers' values as a strategy to gain more investment and attention from fathers through behavioral resemblance.

\section{The role of grandparents' gender and family lineage}

Given that we have found indirect associations between paternal grandfathers' and grandchildren's value dimensions, it seems that paternal family lineage is more influential to G3 
in indirect associations than maternal family lineage. These results do not support our hypothesis based on the discriminative grandparent investment.

Regarding paternal grandparents' sex, grandfathers seem to be more influential. The results revealed more direct associations with mothers and fathers and indirect associations with grandchildren (e.g. individualist values) compared with grandmothers. These results do not support previous studies that found a greater influence of grandmothers (Silverstein \& Marenco, 2001) and of maternal family lineage on grandchildren (Euler \& Weitzel, 1996; Uhlenberg \& Hammill, 1998).

We also found that when considering the influences of G1 on G2, there are more associations between maternal grandparents and mothers for collectivist values. This result can be explained by gender differences in the socialization process: women are more motivated to pay attention and be responsive to others' needs (Zentner \& Renaud, 2007) and are encouraged to give more importance to relational values (Barni et al., 2011).

\section{Limitations}

Although the present study contributes to knowledge on cross-generational trends in values and intergenerational transmission through the analysis of family associations in values, it has several limitations that must be underlined: (1) the sampling was selected through a non-probabilistic sampling strategy, which means that the results cannot be generalized to the Portuguese population; (2) because some questionnaires were mailed and were not completed in the presence of the researchers, we could not ensure that these family members did not discuss their answers, which could lead to an inflation of similarity in scores; (3) only one measure was used to assess values as guiding principles of life, and it was a self-reported measure; therefore it is unclear whether the findings can be generalized to other measures; and (4) although the measure used (SVS) included explicit explanations for each item-value, the measure requires a high level of abstract reasoning, which could be less appropriate for younger adolescents.

Beyond these issues, our study has more two fundamental limitations that undermine our findings: the measurement of G1's values by proxy and the use of mediation modeling with cross-sectional data. The values of G2 and G3 were collected based on self-perceptions, whereas G1's values were indirectly collected through G2's perceptions of their parents' values, so a plethora of factors may affect the accuracy in perception of values - e.g. characteristics of G1 (Schönpflug, 2001), of G2 (Knafo \& Schwartz, 2003), and of the social context (Boehnke, 2001). The proposed mediation is theoretically possible because it could explain the mechanism by which values are transmitted within the family. However, the mediation test would only be appropriate if the current study was longitudinal, which is not the case. Despite this limitation, our results show empirical consistency with the hypothesis of the proposed mediation by using a feasible analytical procedure.

\section{Implications for practice and research}

Our results support the idea of the new generation's greater adoption of individualist values. These results may support the balance between perspectives of social and family decline and solidarity (Bengtson et al., 2002) through a paradox: in families with adolescent children, the maintenance of family capacity to influence the next 
generation and to reinforce cohesion and cooperation is based on the transmission of individualist values. With respect to practice, family clinicians, social workers, educators and forensic technicians should think broadly about intergenerational influences and their consequences and about how to harness families' capacities to strengthen family relationships and the social context, thus promoting individual, familial and social wellbeing. Future research with a more complex methodological design - particularly longitudinal studies with a mixed methodological approach may be necessary to deeply examine the findings of the present study and to understand cross-generational trends in values when adolescents become adults and when they become parents.

Our findings evidenced a clear expansion of the 'restricted' role often attributed to fathers with regard to childcare, which has clear implications in terms of preventive and therapeutic interventions. These findings also lead to another question that deserves research attention: if fathers have a fundamental role in value transmission, who assumes this role and how is it 'compensated' in families with structural configurations in which fathers are absent or do not exist?

This work also suggests that although G2 parents are 'sandwiched' between support for their own parents (G1) and support for the different developmental needs of their adolescent children (G3), they may have a 'bridge role' between the previous generation (grandparents) and the following generation (children). This situation may be very important for the maintenance of collective memory, social functioning and wellbeing, anchoring the family identity and assuring its continuity in time and space (Halbwachs, 1968). In this work, we only consider the role of grandparents' and parents' sex. In future studies, for a better understanding of patterns of intergenerational similarities of values, the role of children's sex should also be studied.

As we mentioned above, in future work our results should be examined using larger samples and more complex methodological designs and data analysis procedures, particularly longitudinal studies, mixed methodologies and diversified measures. Because of the scarcity of research using male samples, future studies should also consider and address this gap to obtain specific knowledge about the role of grandfathers and fathers in the intergenerational transmission of values.

Although the mediation analyses conducted provide empirical support for our hypotheses, other potentially viable untested hypotheses may better account for our data and future research should investigate other means by which values are transmitted across generations. Furthermore, it may be necessary to expand the main focus of the present study on family patterns of intergenerational associations of values across three generations (i.e. intra-family sources and channels of influence) to a focus on the processes of transmission - the resources and strategies in each previous generation that influence the following one (e.g. parental practices and styles, parental attachment, family relationships) as well as, from a circular perspective, the resources and strategies of a generation that influence and change the values of the previous one. In line with this, future studies should test models based on a correlational rather than a predictive approach.

Finally, our study raises an important question: if parents mostly influence their children's individualist values, what sources foster children's adherence to collective values? 


\section{Funding information}

This work was supported through Fundação para a Ciência e Tecnologia [grant number SFRH / BD / 62182 / 2009].

\section{ORCID details}

Ana Prioste (D) http://orcid.org/0000-0001-8881-8963

Isabel Narciso (D) http://orcid.org/0000-0003-0787-7203

Miguel M. Gonçalves (D) http://orcid.org/0000-0003-2575-7221

Cícero R. Pereira (D) http://orcid.org/0000-0003-3406-3985

\section{References}

Axinn, W. G., \& Thornton, A. (1993). Mothers, children, and cohabitation: The intergenerational effects of attitudes and behavior. American Sociological Review, 58, 233-246.

Barni, D., Knafo, A., Ben-Arieh, A., \& Haj-Yahia, M. M. (2014). Parent-child value similarity across and within cultures. Journal of Cross-Cultural Psychology, 45(6), 853-867.

Barni, D., Ranieri, S., \& Scabini, E. (2012). Value similarity among grandparents, parents, and adolescent children: Unique or stereotypical? Family Science, 3(1), 46-54.

Barni, D., Ranieri, S., Scabini, E., \& Rosnati, R. (2011). Value transmission in the family: Do adolescents accept the values their parents want to transmit? Journal of Moral Education, 40, 105-121.

Barreto, J. (2013). Panorama da religião na Europa e em Portugal [Religion in Europe and Portugal contexts]. In A. Araújo (Ed.), 20 anos de opinião pública em Portugal e na Europa (pp. 31-37). Lisboa: Fundação Francisco Manuel dos Santos.

Bengtson, V. L. (2001). Beyond the nuclear family: the increasing importance of multigenerational bonds. Journal of Marriage and the Family, 63, 1-16.

Bengtson, V., Biblarz, T., \& Roberts, R. (2002). How families still matter: A longitudinal study of youth in two generations. Cambridge: University Press.

Berry, J. W., Poortinga, Y. H., Segall, M. H., \& Dasen, P. R. (2002). Cross-cultural psychology: Research and applications (Vol. 2). New York: Cambridge University Press. doi:10.1017/CBO9780511974274

Boehnke, K. (2001). Parent-offspring value transmission in a societal context. Journal of CrossCultural Psychology, 32, 241-255.

Bond, M. H., \& Chi, V. M. Y. (1997). Values and moral behavior in mainland China. Psychologia: An International Journal of Psychology in the Orient, 40, 251-261.

Brofenbrenner, U. (1979). The ecology of human development: Experiments by nature and design. Cambridge, MA: Harvard University Press.

Brooks-Gunn, J., Schneider, W., \& Waldfogel, J. (2013). The great recession and the risk for child maltreatment. Child Abuse and Neglect, 37(10), 721-729.

Caprara, G. V., Schwartz, S., Capanna, C., Vecchione, M., \& Barbaranelli, C. (2006). Personality and politics: Values, traits, and political choice. Political Psychology, 27, 1-28. doi:10.1111/j.14679221.2006.00447.x

Cavalli-Sforza, L. L. (1993). How are values transmitted? In M. Hechter, L. Nadel, \& R. E. Michod (Eds.), The origin of values (pp. 205-317). New York: Aldine de Gruyter.

Cavalli-Sforza, L. L., \& Feldman, M. W. (1981). Cultural transmission and evolution: A quantitative approach. Princeton, NJ: Princeton University Press.

Cavalli-Sforza, L.L., Feldman, M. W., Chen, K. H., Dornbusch, S. M. (1982). Theory and observation in cultural transmission. Science, 218, 19-27. doi:10.1126/science.7123211

Cigoli, V., \& Scabini, E. (2006). Family identity: Ties, symbols, and transitions. Mahwah, NJ: Lawrence Erlbaum Associates.

Conger, K. J., Rueter, M. A., \& Conger, R. D. (2000). The role of economic pressure in the lives of parents and their adolescents: The family stress model. In L. J. Crocket \& R. K. Silbereisen (Eds.), 
Negociating adolescent in times of social change (pp. 201-223). Cambridge, UK: Cambridge University Press.

Constanzo, P. R., \& Hoy, M. B. (2007). Intergenerational relations: Themes, prospects, and possibilities. Journal of Social Issues, 63, 885-902.

Copen, C. \& Silverstein, M. (2008). Transmission of religious beliefs across generations: Do grandparents matter? Journal of Comparative Family Studies, 38, 497-510.

Cronbach, L. J. (1955). Processes affecting scores on "understanding of others" and "assumed similarity". Psychological Bulletin, 52, 177-193.

DeVogli, R. (2014). The financial crisis, health and health inequities in Europe: The need for regulations, redistribution and social protection. International Journal of Equity in Health, 13(58). doi:10.1186/s12939-014-0058-6

Estramiana, J. L., Pereira, C., Monter, M. R., \& Zlobina, A. (2013). Valores Sociais [Social Values]. In L. Camino, A. R. Torres, M. E. O. Lima, \& M. E. Pereira (Eds.), Psicologia Social: temas e teorias (2a Ed.) (pp. 311-355). Brasília: TechnoPolitik.

Euler, H. A., Hoier, S., \& Rodhde, P. A. (2009). Relationship-specific intergenerational family ties: An evolutionary approach to the structure of cultural transmission. In U. Schönpflug (Ed.), Cultural transmission. Psychological, developmental, social, and methodological aspects (pp. 74-94). New York: Cambridge University Press. doi:10.1017/CBO9780511804670

Euler, H. A., \& Weitzel, B. (1996). Discriminative grandparental solicitude as reproductive strategy. Human Nature, 7, 39-59.

Ferreira, S., Pedro, M., \& Francisco, R. (2015). "Entre marido e mulher mete a crise a colher": A relação entre pressão económica, conflito e satisfação conjugal [The relationship between economic pressure, conflict and marital satisfaction]. Psicologia, 29(1), 11-22.

Flor, D. L., \& Knapp, N. F. (2001). Transmission and transaction: Predicting adolescents' internalization of parental religious values. Journal of Family Psychology, 15, 627-645. doi:10.1037// 0893-3200.15.4.627

Friedlmeier, M., \& Friedlmeier, W. (2012). Relative contribution of mothers and fathers to adolescents' values in Romanian families. Cognition, Brian, Behavior: an interdisciplinary Journal, XVI, 239-264.

Friedlmeier, M., \& Trommsdorff, G. (2011). Are mother-child similarities in value orientations related to mothers' parenting? A comparative study of American and Romanian mothers and their adolescent children. European Journal of Developmental Psychology, 8, 661-680.

Ghazarian, S. R., Supple, A. J., \& Plunkett, S. W. (2008). Familism as a predictor of parent-adolescent relationships and developmental outcomes for adolescents in Armenian American immigrant families. Journal of Child and Family Studies, 17, 599-613. doi:10.1007/s10826-007-9177-7

Garnier, H. E., \& Stein, J. A. (1998). Values and the family: Risk and protective factors for adolescent problem behaviors. Youth \& Society, 30, 89-120. doi:10.1177/0044118X98030001004

Geary, D. C. (1998). Male, female: The evolution of human sex differences. Washington, DC, US: American Psychological Association. doi:10.1037/10370-000

Goodwin, R., Realo, A., Kwiatkowska, A., Kozlova, A., Nguyen Luu, L. A., \& Nizharadze, G. (2002). Values and sexual behaviour in Central and Eastern Europe. Journal of Health Psychology, 7, 4556. doi:10.1177/1359105302007001651

Grusec, J. E., \& Goodnow, J. J. (1994). Impact of parental discipline methods on the child's internalization of values: A reconceptualization of current points of view. Development Psychology, 30, 4-19. doi:10.1037//0012-1649.30.1.4

Halbwachs, M. (1968). La Mémoire collective. Paris: Presses Universitaires de France.

Hofstede, G. (1980). Culture's consequences: International differences in work-related values. Beverly Hills: Sage.

Hosley, C. A., \& Montemayor, R. (1997). Fathers and adolescents. In M. Lamb (Ed.), The role of the father in child development (pp. 162-178). New York: Wiley.

van Ijzendoorn, M. H. (1992). Intergenerational transmission of parenting: A review of studies on nonclinical populations. Development Review, 12, 76-99. doi:10.1016/0273-2297(92)90004-L

INE (2013). População residente em risco de pobreza ou exclusão social. Inquérito às Condições de Vida e Rendimento. Retrieved from http://www.ine.pt/xportal/xmain?xpid = INE\&xpgid = ine indicadores\&indOcorrCod $=0006271 \&$ contexto $=\mathrm{bd} \& \operatorname{selTab}=$ tab2 
Inglehart, R. (1977). The silent revolution. Princeton: Princeton University Press.

Jensen, L. A., \& Arnett, J. J. (2012). Going global: New pathways for adolescents and emerging adults in a changing world. Journal of Social Issues, 68(3), 473-492.

Kalish, R. A., \& Johnson, A. I. (1972). Value similarities and differences in three generations of women. Journal of Marriage and the Family, 34, 49-54. doi:10.2307/349629

Knafo, A., \& Schwartz, S. H. (2003). Parenting and adolescents' accuracy in perceiving parental values. Child Development, 74, 595-611. doi:10.1111/1467-8624.7402018

Knafo, A., \& Schwartz, S. H. (2009). Accounting for parent-child value congruence: Theoretical considerations and empirical evidence. In U. Schönpflug (Ed.), Cultural transmission. Psychological, developmental, social, and methodological aspects (pp. 240-268). New York: Cambridge University Press. doi:10.1017/CBO9780511804670

Linares, J. L. (1996). Identidad y narrativa - La terapia familiar en la práctica clínica. Barcelona: Paidós Terapia Familiar.

Menezes, J. \& Campos, B. P. (1991). Estrutura dos valores: estudo transversal [The struture of values: cross-sectional study]. Psychologica, 6, 129-147.

Parke, R. (2002). Fathers and families. In M. H. Bornstein (Eds.), Handbook of parenting: Being and becoming a parent (vol. 3, pp. 27-73). Mahwah, NJ: Lawrence Erlbaum Associates.

Pereira, C., Camino, L., \& Costa, J. B. (2005). Um estudo sobre a integração dos níveis de análise dos sistemas de valores [A study on the integration levels of analysis of value systems]. Psicologia: Reflexão e Crítica, 18, 16-25.

Phalet, K., \& Schönpflug, U. (2001). Intergenerational transmission in Turkish immigrant families: Parent collectivism, achievement values and gender differences. Journal of Comparative Family Studies, 32, 489-504.

Pinquart, M. \& Silbereisen, R. K. (2004). Transmission of values from adolescents to their parents: The role of value content and authoritative parenting. Adolescent, 153, 83-100.

Porter, R. (1987). Kin recognition: Functions and mediating mechanisms. In C. B. Crawford, M. S. Smith, \& D. Krebs (Eds.), Sociobiology and psychology: Ideas, issues and applications (pp. 175203). Hillsdale, NJ: Lawrence Erlbaum.

Pratt, M. W., \& Fiese, B. H. (Eds.) (2004). Family stories and the life course: Across time and generations. Mahwah, N. J.: Erlbaum.

Prioste, A., Narciso, I., \& Gonçalves, M. (2012). Questionário de Valores Pessoais Readaptado: Processo de desenvolvimento e contributos iniciais para a validação [Personal Values Questionnaire Readapted: Development process and initial contributions to the validation]. Revista Iberoamericana de Diagnóstico y Evaluación Psicológica, 34, 175-199.

Prioste, A., Narciso, I., Gonçalves, M., \& Pereira, C. (2015). Family relationships and parenting practices: A pathway to adolescents' collectivist and individualist values? Journal of Child and Family Studies. Journal of Child and Family Studies, 24(11), 3258-3267.

Prioste, A., Narciso, I., Gonçalves, M., \& Pereira, C. (2016). Adolescents parents' values: The role played by retrospective perceptions of the family-of-origin. Journal of Child and Family Studies, 25(1), 224-231.

Ramos, A. (2006). Social values dynamics and socio-economic development. Portuguese Journal of Social Science, 5, 35-64. doi:10.1386/pjss.5.1.35/1

Ranieri, D., \& Barni, S. (2010). Promuovere valori nei figli adolescenti: Uno studio intergenerazionale sulla transmission dei valori in famiglia. Psicologia dell'educazione, 4, 157-176.

Roest, A. M., Dubas, J. S., \& Gerris, J. R. (2009). Value transmission between fathers, mothers, and adolescent and emerging adult children: The role of the family climate. Journal of Family Psychology, 23, 146-155. doi:10.1037/a0015075

Roest, A. M., Dubas, J. S., Gerris, J. R., Engels, R. C. (2009). Value similarities among fathers, mothers and adolescents and the role of a cultural stereotype: Different measurement strategies reconsidered. Journal of Research on Adolescence, 19, 812-833.

Rokeach, M. (1973). The nature of human values. New York: Free Press.

Rosas, F. (2001). O salazarismo e o homem novo: ensaio sobre o Estado Novo e a questão do totalitarismo [The Salazar and the new man: essay on the Estado Novo and the totalitarianism issue]. Análise Social, 35(157), 1031-1054. 
Rosen, B. C. (1964). Family structure and value transmission. Merrill-Palmer Quarterly of Behavior and Development, 10(1), 60-76.

Rothbaum, F., Pott, M., Azuma, H., Miyake, K., \& Weisz, J. (2000). The development of close relationships in Japan and the United States: Paths of symbiotic harmony and generative tension. Child Development, 71, 1121-1142.

Sabatier, C. \& Lannegrand-Willems, L. (2005). Transmission of family values and attachment: A French three-generation study. Applied Psychology: An International Review, 54, 378-395.

Schlegel, A. (2011). Adolescent ties to adult communities: The intersection of culture and development. In L. A. Jensen (Ed.), Bridging cultural and developmental approaches to psychology: New syntheses in theory, research and policy (pp. 138-158). NewYork, NY: Oxford University Press.

Schönpflug, U. (2001). Intergenerational transmission of values: The role of transmission belts. Journal of Cross-Cultural Psychology, 32, 174-185. doi:10.1177/0022022101032002005

Schönpflug, U. (2009). Theory and research in cultural transmission: A short history. In U. Schönpflug (Ed.), Cultural transmission. Psychological, developmental, social, and methodological aspects (pp. 9-33). New York: Cambridge University Press. doi:10.1017/CBO9780511804670

Schönpflug, U., \& Bilz, L. (2009). The transmission process: Mechanisms and contexts. In U. Schönpflug (Ed.), Cultural transmission. Psychological, developmental, social, and methodological aspects (pp. 212-240). New York: Cambridge University Press. doi:10.1017/CBO9780511804670

Schwartz, S. H. (1992). Universals in the content and structure of values: Theoretical advances and empirical tests in 20 countries. In M. P. Zanna (Ed.), Advances in experimental social psychology, (Vol. 25, pp. 1-65). New York: Academic Press.

Schwartz, S. H. \& Bardi, A. (2001). Values hierarchies across cultures: Taking a similiarities perspective. Journal of Cross-Cultural Psychology, 32, 268-290. doi:10.1177/0022022101032003002

Schwartz, S. H., Cieciuch, J., Vecchione, M., Davidov, E., Fischer, R., Beieilein, C., ... Konty, M. (2012). Redefining the theory of basic individual values. Journal of Personality and Social Psychology, 103, 663-688. doi:10.1037/a0029393

Schwartz, S. H., \& Rubel, T. (2005). Sex differences in value priorities: Cross-cultural and multi-method studies. Journal of Personality and Social Psychology, 89, 1010-1028. doi:10.1037/0022-3514.89.6.1010

SEDES (2012). O impacto da crise no bem estar dos portugueses. Associação para o Desenvolvimento Económico e Social. Retrieved from http://www.sedes.pt/documentacao. aspx? args $=2,8 \&$ tipo $=$ artigos\&ID $=61$

Silverstein, M., Giarrusso, R., \& Bengtson, V. L. (2003). Intergenerational solidarity and the grandparent role. In M. Szinovacz (Ed.), Handbook on grandparenthood (pp. 144-158). Westport, Conn: Greenwood Press.

Silverstein, M., \& Marenco, A. (2001). How Americans enact the grandparent role across the family life course. Journal of Family Issues, 22, 493-522. doi:10.1177/019251301022004006

Trommsdorff, G. (2009). Intergenerational relations and cultural transmissions. In U. Schönpflug (Ed.), Cultural transmission. Psychological, developmental, social, and methodological aspects (pp. 126-160). New York: Cambridge University Press. doi:10.1017/CBO9780511804670

Trommsdorff, G. \& Nauck, B. (2006). Demographic changes and parent-child relationships. Parenting: Science and Practice, 6, 343-360. doi:10.1207/s15327922par0604_4

Uhlenberg, P. (2005). Historical forces shaping grandparent-grandchild relationships: Demography and beyond. Annual Review of Gerontology and Geriatrics, 24, 77-97.

Uhlenberg, P., \& Hammill, B. G. (1998). Frequency of grandparents contact with grandchild sets: Six factors that make a difference. Gerontologist, 38, 276-285. doi:10.1093/geront/38.3.276

Vollebergh, W. A. M., Iedema, J., \& Raaijmakers, Q. A. (2001). Intergenerational transmission and the formation of cultural orientations in adolescence and young adulthood. Journal of Marriage and Family, 63, 1185-1198. doi:10.1111/j.1741-3737.2001.01185.x

Voydanoff, P. (1990). Economic distress and family relations: A review of the eighties. Journal of Marriage and Family, 52(4), 1099-1115.

Zal, H. (1992). The sandwich generation: Caught between growing children and aging parents. New York: Insight Books.

Zentner, M., \& Renaud, O. (2007). Origins of adolescents' ideal self: An intergenerational perspective. Journal of Personality and Social Psychology, 92, 557-574. 